\title{
The complexity of cross-sector healthcare teams
}

\section{An interview with Dr Shannon Sibbald}

\author{
Alice Yi, Dino D'Andrea \\ Faculty Reviewer: Shannon L Sibbald, PhD (Department of Family Medicine)
}

\section{INTRODUCTION}

Dr Shannon Sibbald is a health systems researcher specializing in implementation science, the study of factors that affect the implementation and success of new practices, as well as interprofessional teamwork in healthcare settings. She also spends time teaching students in the Masters of Public Health program and has held faculty positions in the Department of Family Medicine, Schulich Interfaculty Program of Public Health, and School of Health Studies since 2013. We were able to sit down with Dr Sibbald for our interview to discuss her work in health systems and policy.

\section{UWOMJ: Can you tell us about your educational background} and how you became a part of the Western faculty?

Dr Shannon Sibbald: I did my undergrad in Bachelor of Health Sciences program here, at Western. When I was here I had the opportunity to work with phenomenal mentors and faculty, and one of my mentors, Dr. Louis Charland, really helped me understand how much I enjoyed research. Like many students who start the BHSc program, I thought I wanted to be a doctor! My interests changed as the program allowed me to look at health from a different perspective-as a holistic concept as opposed to just a biomedical concept. I spent summers working at the University of Toronto Joint Centre for Bioethics, and that's where I ended up doing both my Masters and PhD. I was in the Institute of Health Policy, Management, and Evaluation, with a subspecialty in Bioethics. I returned to Western to work with Dr Anita Kothari and Dr Nadine Wathen and did a three-year postdoctoral fellowship, during which I began focusing my time more on cross-systems and intersectoral work. So while my graduate studies were heavily focused in acute care in hospitals, I started looking more at other sectors like public health, primary care, and long-term care, and began to understand truly how complex our health system is. After then, I did a six-month post-doc with the International Center for Health Innovation and Leadership out of Ivey, and at that time a position came up that involved working with the Department of Family Medicine, the Schulich Interfaculty Program of Public Health, and the School of Health Studies. It was perfect-it was everything I'd been doing up until this point all wrapped up into one perfect role! The job allows me to continue working in interdisciplinary and cross-sector research, and I've been here since 2013.

\section{What drew you towards interdisciplinary health systems re- search?}

I really want to help people-to help patients, but knowing that I didn't have a clinical interest made me think, "What can my contribution be instead?" And I think I'm good at research; I enjoy it, whether it be coming up with a research question on my own or being involved with integrative knowledge translation. I try to be involved with knowledge users-policy makers, physicians, people who are using the knowledge on the ground-and come up with research questions that will ultimately and hopefully impact their day-to-day practice, which then in turn impacts patient care. I'm drawn to new, innovative, changing, and dynamic systems, and that's what healthcare is. There's always new policies, new legislations, grey papers, or political promises. There's always something going on that's affecting the health of Canadians, so to be a part of that but at the same time use my own strengths was what really drew me into health systems research.

\section{Could you tell us about your current research?}

In order to understand the complexity of the health system, it is necessary to understand each of the working pieces and how they function. My goal right now is to try and understand how teams function within healthcare. Whether or not teams are the best approach to handle a scenario is kind of up to debate. Dr Natalie Allen, a great researcher here on campus, has a paper called "The Romance of Teams," where she says teams aren't always the best approach; it depends on a number of factors. In healthcare though, it's the reality-whether or not teams are the best from an evidentiary point of view, we do a lot of things using teams, and that largely comes down to the right mix of health professionals along with task complexity and financial costs. We know that a service delivered by a personal support worker is going to be more cost-effective than a service offered by a physician, so we need to figure out how to best deliver care in a team-based way. With that in mind, I am trying to understand what team-based care looks like across primary care and hospital care.

I'm looking at patients with complex care needs, like with COPD. These patients need a team that can work across the sectors. They need a primary care team, an acute care team for when they need to be in the hospital, and many of them also have long term and home care needs. We're getting really good at team based care in a hospital, with a classic example being a surgical team. Those teams have in some ways learned how to do it really well. Even in primary care we're getting better at understanding what a team should look like. But what does a team look like that has to navigate across those sectors?

We're looking at what we are calling high-performing teams. They have the right mix of health professionals, and they're working in a way that's effective and efficient. How have they figured it out, and what's the secret? We hope we 
can understand their secret to success and share those lessons with other teams who are trying to do a similar task.

\section{What does the current average cross-sector team for COPD care look like?}

The answer is we don't know yet; there's not a lot of consistency. We have 14 Local Health Integration Network (LHINs) in Ontario, and in just our LHIN alone we're trying to categorize all the different COPD programs available. And COPD is complex because there are multiple stages. Something that might work for someone with early stage COPD in the community would not work for someone who has late stage COPD and needs care in the home.

There are some exemplars out there. For example, I've done work with the Canadian Foundation for Health Care Improvement and they recently did a quality improvement collaborative project called the INSPIRED COPD Outreach Program. ${ }^{2}$ That was their attempt at a cross-sector, inter-professional, inter-disciplinary, patient-centered team. We're in the process of evaluating the impact of those teams. What happened to allow some teams to do so well, while others never got off the ground?

\section{Are there any countries or provinces other than Ontario that has a successful intersectional teamwork model?}

The example I gave you earlier of INSPIRED actually comes from Nova Scotia. But in terms of what's really happening, we don't know yet. My goal is to reach out to colleagues in other provinces to start those discussions. Even in London, there is so much diversity. I think that's a good thing, because that means that patients potentially have access to this diversity of programs. But the challenge comes when there's not a program in their area that's right for them, and this can be because of many factors like disease stage, access, or patients' wishes. So the multitude of programs can be seen as a good thing, but the fact that those programs are not well coordinated is where we have a challenge.

\section{What is the biggest barrier to creating an effective integrated system?}

We have historically provided healthcare in silos, and unfortunately the silos are perpetuated by the way they're funded. It becomes really challenging to make a change when at the end of the day you still have to pay for the services somehow. Who owns this intersectoral healthcare team? Acute care probably doesn't think they own it because it's not happening in the hospital, even though these patients eventually end up at their front door! Primary care is often willing to own it but they need the support of other sectors. It's really difficult to coordinate when the systems are not very integrated. I think that's one of the biggest challenges, but I also think we currently have an opportunity with changes coming down the pipe with Patients First Act. ${ }^{3,4}$

\section{What's the current state of education in terms of interprofes- sional, team-based learning?}

I'm very interested in team-based learning. I have this hypoth- esis that if we are training all of our health professionals in a teambased learning approach, they'll work better at point-of-care in a team based case approach. Another long-term goal of mine is to test out this hypothesis. It's important to educate people on the complexities of the systems, but we also need to teach people how to function within a complex system. We're not going to change how complex the system is, so we need to teach people how to work within it.

Here at Western, all the learning in the MPH program is team-based. We have a strong competency-based and casebased curriculum, and we are using it as a living laboratory to test out some of those assumptions. There's a lot of literature around inter-professional education, but oftentimes that literature focuses more on inter-professional education once people are already working. What I'm suggesting is maybe we need to start evaluating inter-professional education a little earlier in the classroom in graduate and undergraduate training.

\section{Do you have any advice for medical students or students in general who are interested in health systems?}

Don't be afraid to challenge the system. No matter what area you go into, as a doctor there's always an open door to challenge the system. If you see something that's not right in the system, or if you see a way to make it better, to do it because you have that credibility to make things happen. And that's why I feel very fortunate to be jointly appointed in the Department of Family Medicine, because I have the ability to sit down with family doctors and find out what is actually happening on the ground. I can only speak from my research perspective and what I see happening is from a systems point of view, whereas the clinicians actually live it.

\section{FURTHER READING}

1. Allen NJ, Hecht TD. The "romance of teams": Toward an understanding of its psychological underpinnings and implications. Journal of Occupational and Organizational Psychology. 2004;77:439-61.

2. Nova Scotia Health Authority. The INSPIRED COPD Outreach Program [Internet]. Nova Scotia Health Authority. [Cited 2017 Apr 30]. Available from http://www.cdha.nshealth.ca/chronic-obstructive-pulmonary-disease-copd/patients/inspired-copd-outreach-program.

3. Legislative Assembly of Ontario. Bill 41, Patients First Act, 2016 [Internet]. Legislative Assembly of Ontario; 2016 Dec 6 [Cited 2017 Apr 30]. Available from: http://www.ontla.on.ca/bills/bills-files/41_Parliament/Session2/b041ra.pdf.

4. Ontario Ministry of Health and Long-Term Care. Patients First: Action Plan for Health Care [Internet]. Ontario Ministry of Health and LongTerm Care; 2017 Apr 19. [Cited 2017 Apr 30]. Available from: http:// www.health.gov.on.ca/en/ms/ecfa/healthy_change/. 